See Article page 226.

\section{Commentary: Refining the reimplantation technique for anomalous aortic origin of a coronary artery}

Harold M. Burkhart, MD, ${ }^{\mathrm{a}}$ Yuki Nakamura, $\mathrm{MD},{ }^{\mathrm{a}}$ and Shashank P. Behere, MD ${ }^{b}$

Anomalous aortic origin of a coronary artery (AAOCA) may be associated with myocardial ischemia and sudden cardiac death in the presence of high-risk anatomic characteristics. The most common pathological variant involves the right coronary artery arising from the left sinus of Valsalva (AAORCA). Surgical intervention is typically recommended if there are signs or symptoms of myocardial ischemia or if there is inducible ischemia with exercise testing. ${ }^{1}$ Although several surgical approaches, including unroofing, pulmonary artery translocation, osteoplasty, bypass grafting, and reimplantation, have been described, superiority of 1 technique over the others has not been established. ${ }^{1-3}$

Grau and colleagues ${ }^{4}$ describe their preferred surgical approach to AAORCA. Advocating for surgical transection and reimplantation into the respective sinus, they detail their technique and point out critical maneuvers to ensure a good outcome. Key technical points include:

- Dissection of the right coronary artery for 1.5 to $2 \mathrm{~cm}$ for mobility and avoiding tension at reimplantation,

- Selecting a high reimplantation site with the heart beating to avoid kinking,

From the a Division of Cardiovascular and Thoracic Surgery and ${ }^{\mathrm{b}}$ Section of Pediatric Cardiology, University of Oklahoma Health Sciences Center, Oklahoma City, Okla.

Disclosures: The authors reported no conflicts of interest.

The Journal policy requires editors and reviewers to disclose conflicts of interest and to decline handling or reviewing manuscripts for which they may have a conflict of interest. The editors and reviewers of this article have no conflicts of interest.

Received for publication Feb 7, 2021; revisions received Feb 7, 2021; accepted for publication Feb 17, 2021; available ahead of print Feb 20, 2021.

Address for reprints: Harold M. Burkhart, MD, Division of Cardiovascular and Thoracic Surgery, University of Oklahoma Health Sciences Center, PO Box 26901, WP-2230, Oklahoma City, OK 73105 (E-mail: Harold-burkhart@ouhsc. edu).

JTCVS Techniques 2021;7:231-2

2666-2507

Copyright (C) 2021 The Authors. Published by Elsevier Inc. on behalf of The American Association for Thoracic Surgery. This is an open access article under the CC BY-NCND license (http://creativecommons.org/licenses/by-nc-nd/4.0/).

https://doi.org/10.1016/j.xjtc.2021.02.020

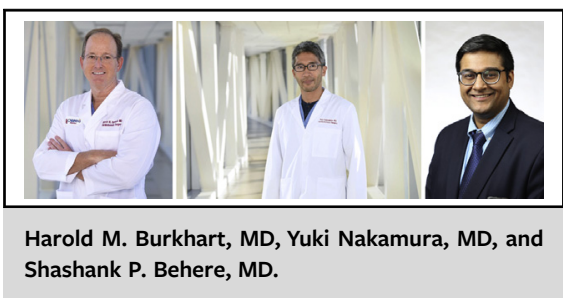

CENTRAL MESSAGE

Transection and reimplantation

of anomalous aortic origin of a

right coronary artery is a

technique with which all cardiac

surgeons should be familiar.

- Performing a transverse aortotomy to confirm the proposed reimplantation site is appropriately away from the aortic valve, and

- Assessing right coronary flow dynamics postimplantation.

In addition, they make a point of obtaining cardiac computed tomography scans as well as a nuclear stress test before discharge and unrestricted activities. Overall, the authors should be congratulated on delineating the key steps to successfully repairing AAORCA with a transection and reimplantation approach.

Currently, the most common surgical technique for AAOCA seems to be surgical unroofing, with $87 \%$ of 395 patients undergoing this approach in a recently published Congenital Heart Surgeons' Society study. ${ }^{2}$ In this same group of patients, only $6 \%$ underwent reimplantation, with or without the use of an aortic button. The distinction of transection and reimplantation versus translocating with an aortic button is an important point. Although utilizing a button with a smaller right coronary artery may be appealing, issues such as the need for commissural manipulation and the presence of a slit-like orifice may make this approach less attractive. The method of transecting the coronary artery and reimplanting obviates the intramural and commissural concerns, making this technique appealing, especially if the vessel is of reasonable size. Bonilla-Ramirez and colleagues ${ }^{5}$ recently published on their experience utilizing reimplantation in 16 of 61 patients treated surgically for AAOCA. There was no early or late mortality, although 1 patient required a saphenous vein bypass graft following 
reimplantation. They advocated for the use of reimplantation in patients with a coronary course below the aortic valve commissure, when unroofing does not relocate the ostium to the correct sinus or when it does not alleviate intercoronary pillar compression.

The authors report an excellent technical description of the transection and reimplantation approach to AAORCA. We have learned a great deal about the surgical management of these at-risk patients during recent years, and it has become clear that no single surgical technique will suffice. This techniques article provides a superb description to a procedure that should be included in all congenital cardiac surgeons' armamentarium.

\section{References}

1. Brothers JA, Frommelt MA, Jaquiss RDB, Myerburg RJ, Fraser CD, Tweddell JS Expert consensus guidelines: anomalous aortic origin of a coronary artery. $J$ Thorac Cardiovasc Surg. 2017;153:1440-57.

2. Jegatheeswaran A, Devlin PJ, Williams WG, Brothers JA, Jacobs ML, DeCampli WM, et al. Outcomes after anomalous aortic origin of a coronary artery repair: a Congenital Heart Surgeon's Society study. J Thorac Cardiovasc Surg. 2020;160:757-71.e5

3. Sharma V, Burkhart HM, Dearani JA, Suri RM, Daly RC, Park SJ, et al. Surgical unroofing of anomalous aortic origin of a coronary artery: a single-center experience. Ann Thorac Surg. 2014;98:941-5.

4. Grau JB, Rahmouni K, Castillo J, Ruel M, Maharajh G. Reimplantation for anomalous right coronary artery. J Thorac Cardiovasc Surg Tech. 2021;7:226-8.

5. Bonilla-Ramirez C, Molossi S, Sachdeva S, Reaves-O'Neal D, Masand P, Mery CM, et al. Outcomes in anomalous aortic origin of a coronary artery following surgical reimplantation. J Thorac Cardiovasc Surg. January 5, 2021 [Epub ahead of print]. 